
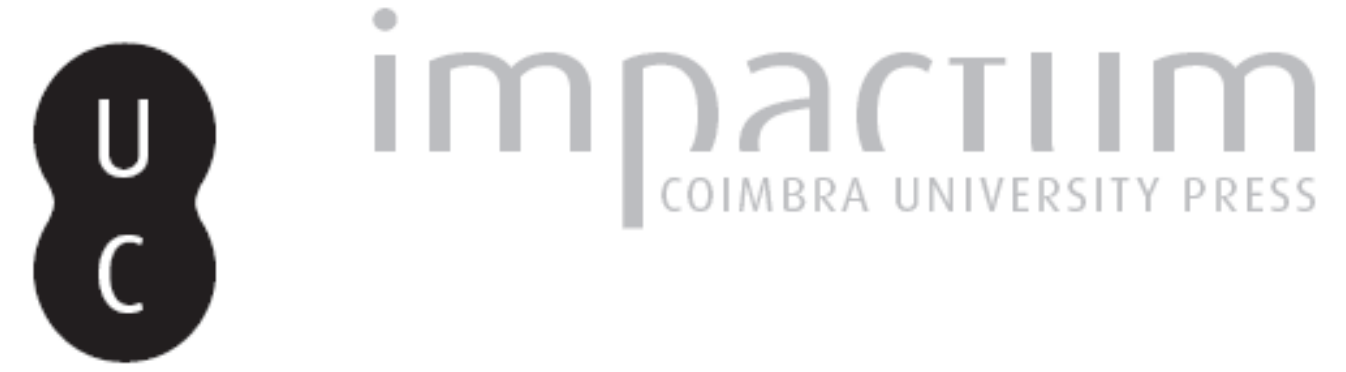

\title{
A criação de serviços de informação para refugiados: uma necessidade e uma oportunidade para o futuro
}

\author{
Autor(es): $\quad$ Almeida, Filipa Rino
}

Publicado por: Imprensa da Universidade de Coimbra

URL persistente:

URI:http://hdl.handle.net/10316.2/43074

DOI:

DOI:http://dx.doi.org/10.14195/0870-4112_3-3_6

Accessed : $\quad$ 26-Apr-2023 04:54:49

A navegação consulta e descarregamento dos títulos inseridos nas Bibliotecas Digitais UC Digitalis, UC Pombalina e UC Impactum, pressupõem a aceitação plena e sem reservas dos Termos e Condições de Uso destas Bibliotecas Digitais, disponíveis em https://digitalis.uc.pt/pt-pt/termos.

Conforme exposto nos referidos Termos e Condições de Uso, o descarregamento de títulos de acesso restrito requer uma licença válida de autorização devendo o utilizador aceder ao(s) documento(s) a partir de um endereço de IP da instituição detentora da supramencionada licença.

Ao utilizador é apenas permitido o descarregamento para uso pessoal, pelo que o emprego do(s) título(s) descarregado(s) para outro fim, designadamente comercial, carece de autorização do respetivo autor ou editor da obra.

Na medida em que todas as obras da UC Digitalis se encontram protegidas pelo Código do Direito de Autor e Direitos Conexos e demais legislação aplicável, toda a cópia, parcial ou total, deste documento, nos casos em que é legalmente admitida, deverá conter ou fazer-se acompanhar por este aviso.

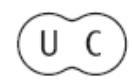




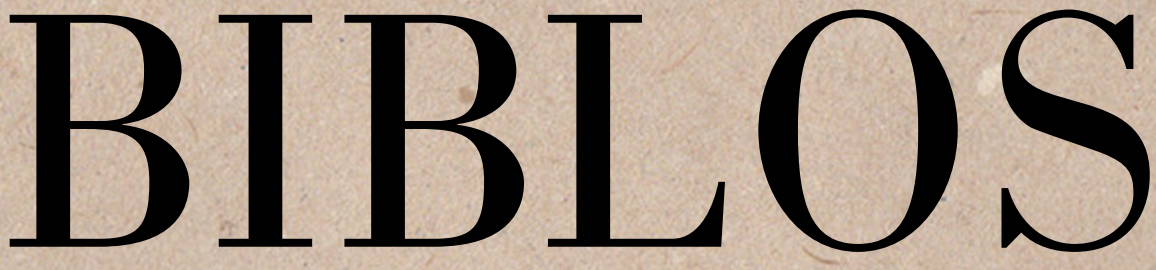

Revista da Faculdade de Letras da Universidade de Coimbra

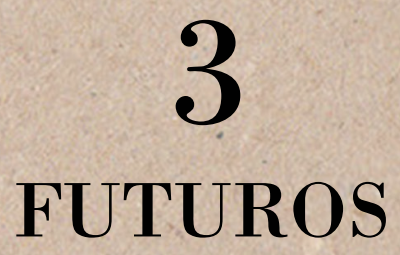

NÚMERO 3, 2017

3. ' SÉRIE 


\title{
A CRIAÇÃO DE SERVIÇOS DE INFORMAÇÃO PARA REFUGIADOS: UMA NECESSIDADE E UMA OPORTUNIDADE PARA O FUTURO
}

\author{
The creation of refugee information \\ services: an unmet need \\ and future opportunity
}

FILIPA RINO ALMEIDA

flipa.r.almeidax@gmail.com

Faculdade de Letras da Universidade de Coimbra

DOI
https://doi.org/10.14195/0870-4112_3-3_6

Recebido em setembro de 2016

Aprovado em dezembro de 2016

Biblos. Número 3, 2017 • 3.a Série

pp. $123-147$ 


\title{
RESUMO.
}

A atual crise dos refugiados foi o mote para este trabalho. Nos últimos anos, sobretudo devido ao conflito sírio milhares de refugiados têm chegado à Europa. Aqui, procuram-se agora soluçōes para conseguir socorrer e integrar estas pessoas. O objetivo deste artigo é alertar para a necessidade de criar planos de integração dos refugiados que incluam as bibliotecas públicas, através da criação de serviços de informaçâo multiculturais. Para a sua elaboraçâo foi fundamental analisar relatórios e web sites de entidades como o ACNUR, o CPR e o SEF, bem como manifestos e normas da IFLA/UNESCO para a implementação de serviços de informação. Conclui-se que a integração das bibliotecas públicas nos planos de acolhimento é uma mais-valia devido ao seu elevado potencial informacional e cultural. Conclui-se também, que urge criar um serviço de informação para refugiados de modo a centralizar a informação e fornecer um serviço adaptado às suas necessidades.

Palavras-chave: Serviços de informação; Refugiados; Acolhimento; Europa; Bibliotecas públicas.

\begin{abstract}
.
The current refugee crisis was the driving force behind this paper. In recent years, mainly due to the Syrian conflict thousands of refugees have arrived in Europe. We are now faced with the task of searching for solutions to get assist and integrate these people. The purpose of this paper is to rise awereness of the need for refugee integration plans that include public libraries, through the creation of multicultural information services. We analysed reports and web sites from organisations such as the UNHCR, the CPR and the SEF (Portuguese Boarder Agency), as well as manifests and rules of IFLA/UNESCO manifestos and guidelines on the implementation of information services. We conclude that the integration of public libraries in the refugee reception plans is an advantage due to its high informational and cultural potential. We also conclude that there is an urgent need to create an information service for refugees to centralise information and provide their needs.
\end{abstract}

Keywords: Information services; Refugees; Reception; Europe; Public libraries. 


\section{INTRODUÇÃO}

Nos últimos anos temos assistido a um aumento de conflitos duradouros que têm consequências nefastas ao nível local, e cada vez mais a nível global. Desde logo o aumento de deslocados internos e de refugiados, depois o facto dos conflitos se prolongarem não permite o regresso das pessoas, obrigando-as a fugir. Muitas vão para os países vizinhos, na maior parte dos casos, países pouco desenvolvidos. O resultado é um amontoado de seres humanos em campos de refugiados completamento lotados.

Para os refugiados africanos e do médio oriente, devido à proximidade geográfica, a Europa é um sonho americano e é para aqui que se têm deslocado de forma intensiva nestes últimos dois anos. Com milhares de refugiados às portas da Europa é preciso agir rapidamente: urge encontrar soluçôes duradouras para estas pessoas. Uma das soluçôes é a sua recolocação pelos diversos países europeus promovendo a sua integração local, algo que já tem vindo a ser posto em prática nos últimos anos.

Neste processo o acesso à informação e a sua correta assimilação é essencial para refugiados e para as populaçôes nativas, por forma a promover uma cultura de respeito, desfazendo o medo e ideias preconcebidas. É este o objetivo dos serviços de informação para refugiados. Este artigo mostra a importância que estes serviços podem ter a nível local para a integração dos refugiados, sendo a sua criaçáo uma prioridade.

\section{BREVE SINOPSE HISTÓRICA: O PERÍODO DA II GUERRA MUNDIAL}

Antes de enveredar por esta investigação é necessário fazer uma breve contextualização histórica sobre o conflito que está por detrás daquela que era, até agora, considerada a maior crise de refugiados da História: a II Guerra Mundial.

Este conflito mundial, entre 1939 e 1945, dividiu a Europa e o resto do mundo, opôs a Alemanha, chefiada por Hitler e os seus aliados, em especial a Itália e o Japão, às chamadas forças do Eixo, à Inglaterra, França e, mais tarde, URSS e EUA, entre outros países, formando os Aliados (Gilbert 2010: 251-301). A guerra desenvolveu-se em várias frentes, sobretudo devido à po- 
lítica expansionista e antissemita levada a cabo por Hitler que invadindo na Europa a Checoslováquia, Áustria, Polónia, Jugoslávia e a França, procurava criar o que chamava de "espaço vital", necessário para afirmar a supremacia da raça ariana ${ }^{1}$. Preconizando o nazismo, Hitler defendia a superioridade da raça ariana sobre todas as outras e a exterminação dos judeus. Neste sentido, foram criadas leis antissemitas, das quais se destacam as Leis de Nuremberga e criados campos de concentração provocando a morte a cerca de 6 milhóes de judeus. Sem sucesso, Hitler procurou ainda, juntamente com Mussolini, alcançar o domínio do norte de África e da Rússia. Por outro lado, a oriente, China e Vietname travaram a chamada Guerra da Manchúria com o Japáo, a que se juntou os EUA após o ataque japonês a Pearl Harbor em 1942 (ib.). Após este ataque aos EUA e à invasão da Rússia por Hitler, estas duas potências uniram-se aos Aliados, provocando uma reviravolta inesperada na guerra que até então parecia ganha pelas forças do Eixo. Após o desembarque das tropas aliadas na Normandia no verão de 1944, a vitória dos Aliados tornou-se eminente, terminando a guerra em 1945 com a vitória dos Aliados (ib.).

Em 1945 a Europa estava de rastos, destruída política, económica, social e culturalmente. Na Manchúria, o Japáo foi o principal derrotado, sendo que ali a guerra terminou de forma abrupta com a detonação de duas bombas atómicas, respetivamente, a 6 e 9 de Agosto de 1945, na cidades de Hiroxima e Nagasáqui, fazendo ao todo mais de 180 mil mortos, sendo que os efeitos da radiação permaneceram por décadas $(i b$.). No fim da guerra, o balanço foi desastroso: milhôes de mortos, calcula-se que cerca de 33 milhóes de pessoas

A ideia da existência da "raça ariana", derivava da eugenia, uma teoria que defendia que era possível controlar as qualidades genéticas humanas, podendo aperfeiçoá-las, através da seleção controlada de seres humanos considerados superiores, incentivando a sua reproduçáo e da extinção dos seres humanos considerados imperfeitos, por seres portadores de deficiências (Judt 2007: 391). Influenciado por esta e outras teorias semelhantes, Hitler defendia que a "raça ariana" era composta pelos povos dos países nórdicos que eram, genericamente, altos, louros e de olhos azuis e, por isso, considerados uma "raça superior" às outras, sendo os judeus considerados "inferiores" e acusados de degenerarem esta "raça". Pode ler-se mais sobre estes conceitos e a ideologia racial nazi em United States Holocaust Memorial Museum (2016). 
entre soldados, marinheiros, aviadores, prisioneiros de guerra, civis (10 milhóes, dos quais, 6 milhóes eram judeus) (ib.: 300-301).

Para além dos mortos, um conflito desta dimensão provocou milhóes de desalojados devido aos bombardeamentos e uma grande crise de refugiados. Estes eram na sua maioria judeus, que fugiam da Europa rumo, sobretudo à Palestina. Por outro lado, no fim da guerra, houve deslocaçóes em massa de alemães e polacos devido aos acordos de Potsdam que determinavam a divisão da Alemanha. Todos os alemães que viviam em países que haviam sido ocupados pela Alemanha durante a guerra foram obrigados a sair destes territórios, para dar lugar aos polacos que agora tinham direito a eles. Nas palavras de Martin Gilbert:

A conferência de Potsdam acordou especificamente na "retirada dos alemães da Polónia, Checoslováquia e Hungria”. Estes alemães já estavam em retirada, formando um imenso contingente de refugiados. Em consequência da anexação da Polónia Oriental pela União Soviética, milhôes de polacos estavam também em debandada, a caminho das partes da Alemanha que tinham sido transferidas para a Polónia. Milhôes de alemães e povos de língua alemã foram expulsos pelos soviéticos, polacos e checos de regióes onde viviam há muitas geraçóes. A Prússia Oriental estava a ser limpa dos seus habitantes alemáes, em preparaçáo para a partilha e ocupação por russos e polacos. Os Sudetas estavam a ser esvaziados dos seus alemães sudetas para que os checos pudessem lá viver.

(Gilbert 2010: 297-298)

Entre 1945 e 1957, quando fechou o último campo de refugiados, foi necessário gerir milhares de refugiados. Na Alemanha, no final de 1945 havia 227 campos e centros de auxílio a refugiados e deslocados. Mais tarde, em 1947, existiam já 762 campos na Europa Ocidental. Sem contar com a populaçáo das forças do Eixo, havia 6795000 civis libertados a cargo das Naçóes Unidas ou repatriados pela UNRRA (United Nations Relief and Rehabilitation Administration). Havia ainda cerca de 7 milhóes de refugiados sobre autoridade soviética (Judt 2007: 50). Como referido, muitos eram judeus, sendo que entre 
1948 e 1951, 332000 judeus deslocaram-se para Israel e 165 mil para França, Grã-Bretanha, Austrália e Américas do Norte e do Sul (ib.). Ao todo, entre judeus, refugiados políticos alemães e polacos e outros que decidiram abandonar a Europa, chegaram aos EUA 400000 mil pessoas até 1953, chegando depois mais 185000 até 1957. O Canadá permitiu a entrada de 157000 refugiados e deslocados e também a Austrália recebeu 182000 mil pessoas (ib.: 54).

Após a guerra foi imperativo repensar o mundo, em geral, e a Europa, em particular. A II Guerra Mundial deixou marcas profundas e uma enorme vontade de que tão cedo não voltasse a suceder algo semelhante. Neste sentido, houve uma reflexáo acerca da condição humana e da necessidade de proteger os cidadãos, garantindo-lhes melhores condiçóes de vida, sobretudo na doença, no desemprego, na viuvez e/ou orfandade e na velhice. Assim, começou a ser implementado na Europa um sistema de proteção social, designado por Estado Providência que previa a existência de um serviço nacional de saúde, subsídios para acautelar situações de doença, velhice ou desemprego, educação gratuita e programas de habitação social. Em suma, pretendia-se criar condiçóes de vida mais equitativas e aumentar a qualidade de vida dos europeus (Fraser 2009: 14).

Com o propósito de alertar para as violaçóes dos Direitos Humanos, que foram uma constante durante a guerra, e no esforço da sua erradicação ou pelo menos da sua atenuação, foi aprovada pelas Naçóes Unidas, a 10 de Dezembro de 1948, a Declaração Universal dos Direitos do Homem. Nela estáo consignados 30 direitos e deveres básicos para que qualquer ser humano possa viver dignamente (Diário da República Eletrónico 2016): o direito à não discriminação, à igualdade de tratamento, à educação, à liberdade de expressão, ao respeito pela integridade da pessoa humana, à habitação, à livre deslocação para qualquer parte do mundo, etc., e são condenados atos de violência ou de desrespeito pelo ser humano (Gilbert 2010: 315). Esta declaração é até aos dias de hoje o principal referencial no que diz respeito aos Direitos Humanos.

Por fim, e tendo em conta o contexto de crise de refugiados que se vivia na altura, a 28 de Julho de 1951 foi aprovada pela Organização das Naçóes Unidas (ONU), a Convenção relativa ao estatuto dos refugiados, em Genebra. Nesta convenção está estabelecido o estatuto de refugiado, os seus direitos e de deveres, bem como os dos Estados que a ratificaram. Também esta convenção 
continua hoje a ser um marco importante para a concessão do direito de proteção internacional e asilo ${ }^{2}$. Tendo ficado estabelecida, no Capítulo I, artigo $1 .^{\circ}$, a definição de refugiado:

Para os fins da presente Convenção, o termo "refugiado" se aplicará a qualquer pessoa: [...] que, em consequência dos acontecimentos ocorridos antes de $1 .^{\circ}$ de janeiro de 1951 e temendo ser perseguida por motivos de raça, religião, nacionalidade, grupo social ou opinióes políticas, se encontra fora do país de sua nacionalidade e que não pode ou, em virtude desse temor, não quer valer-se da proteção desse país, ou que, se não tem nacionalidade e se encontra fora do país no qual tinha sua residência habitual em consequência de tais acontecimentos, não pode ou, devido ao referido temor, não quer voltar a ele.

(ACNURb ${ }^{3}$ 2016: 2)

Esta definição deixa bem claro, que o refugiado não é um migrante comum que se desloca para fora do seu país por vontade própria, é sim uma pessoa que é forçada a fugir de cenários de guerra, de violência ou de perseguição, temendo que o seu país não consiga garantir os seus direitos, liberdades e garantias.

\section{A CRIAÇÁO DE SERVIÇOS DE INFORMAÇÃO EM CONTEXTO DE GUERRA: O EXEMPLO DOS CITIZENS ADVICE BUREAU}

A ação de criar está por norma associada a um propósito e a uma necessidade de mudança, de testar novas soluçóes e de fazer a diferença. Ora, apesar do cenário de guerra e de conflitos armados possa parecer infértil para construir algo bom e diferente, é precisamente aqui que necessidades não faltarão.

\footnotetext{
2 A convenção está disponível em ACNUR (2016b).

3 O Alto Comissariado das Nações Unidas para os Refugiados (ACNUR) foi fundado em 1950 com o objetivo de proteger os refugiados e arranjar resoluçôes efetivas para que estes possam refazer as suas vidas, num ambiente pacífico e estável. Para saber mais acerca desta organização aceda-se a ACNUR (2016a).
} 
O essencial é reinventarmo-nos, fazer muito com pouco e adaptar pessoas e recursos à realidade, para a tornar melhor.

Ora foi precisamente isso que os Citizens Advice Bureau (CAB) fizeram há cerca de 70 anos atrás. Surgiram durante a II Guerra Mundial em Inglaterra ${ }^{4}$, perante a necessidade de ajudar as pessoas a solucionar problemas relacionados com a guerra (Citizens Advice Bureau 2009: 4-5). O lema era: "aliviar a aflição pessoal e confusão, fornecendo, gratuitamente, conselho ou informação confidencial, imparcial e independente sobre qualquer assunto a qualquer pessoa que o pedir." (Working Party on Community Information 1980: 14). Nesta altura, como na atualidade, a informação corretamente transmitida é absolutamente essencial. Em 1939 era essencial por defeito, havia falta de informação. Um rádio era um bem precioso, os correios eram lentos e em guerra, intermitentes. Hoje a informação é fundamental por excesso. Há uma variedade tão grande de formas de comunicar, de fontes e de suportes de informação que causa um autêntico caos sempre que queremos dominar determinada matéria ou obter alguma informação. Somos informados, contrainformados e desinformados, tudo ao mesmo tempo. Precisamos cada vez mais de alguém que nos ajude a desatar os nós deste enorme novelo informativo. Se nós cidadãos no nosso país de origem, dominando a nossa língua materna, com acesso total a meios de informação temos cada vez mais dificuldades na resolução de questôes burocráticas, o que dirá um refugiado, com uma língua e cultura diferentes, onde muitas vezes, não há pleno acesso à informação?

O principal entrave que se coloca hoje à criação destes serviços é a falta de recursos financeiros e humanos, que muitas vezes são apenas um reflexo

\footnotetext{
A 3 de Agosto de 1939 a fundação dos CAB em Londres era noticiada na BBC: "The National Council for Social Services has drawn up plans to set up what they call a 'Citizens' Advice Bureau' in London and other large cities and towns if war does break out. The bureaux will act as clearing houses for family and personal problems that arise from war conditions. They will give advice on what to do if your home is damaged during an air raid or how to get in touch with your children if they are evacuated" (Citizens Advice Bureau 2009: 4). Os CAB foram depois, rapidamente instituídos na Irlanda do Norte e na Escócia, onde só nas décadas de 70 e 80 do séc. XX, passam a ter uma gestão autónoma. No entanto, foi e continua a ser em Inglaterra que têm maior expressão (Almeida 2015: 47-48).
} 
de falta de vontade política e social de fazer diferente. Também em 1939 esta questão se punha. Para a combater, estes serviços começaram apenas com 200 postos de atendimento, muitos deles ambulantes, criados em colaboração com as instituiçóes locais. No entanto, os $\mathrm{CAB}$ depressa se tornaram essenciais e, logo em 1942, chegaram aos 1000 gabinetes espalhados por todo o Reino Unido (Citizens Advice Bureau 2009: 5).

Depois, este serviço que parecia útil só em contexto de guerra soube adaptar-se a novos contextos, e tornou-se na maior agência de prestação de serviços de informação à comunidade do país, expandindo-se para outros países anglo-saxónicos. Hoje, 77 anos depois, os CAB são uma referência mundial.

Porque não implementar em Portugal um serviço de informação para refugiados? Temos todas as condiçóes: o motivo que é a vinda de, pelo menos 4593 refugiados (Gonçalves 2015) e a necessidade de os integrar da forma mais humana e eficaz possível. Apesar da atual escassez de recursos, é preciso reunir esforços e agarrar esta oportunidade de reinventar os serviços de informação e o papel das bibliotecas públicas na sociedade.

\section{A ATUAL CRISE DOS REFUGIADOS}

Não foi por acaso que, em Portugal, a palavra do ano, escolhida no final de 2015 foi... refugiado. Este assunto que está na ordem do dia em todos os países da Europa, após a chegada de milhares de refugiados. Analisando aprofundadamente este assunto percebemos que a vinda de refugiados para a Europa é apenas a ponta do iceberg desta crise humanitária.

De onde vêm tantos refugiados? Porque vêm? Porquê agora? A resposta está na existência de cada vez mais conflitos, que se têm prolongado no tempo em várias partes do mundo (OECD 2015). De acordo com o ACNUR, nos últimos cinco anos começaram ou reiniciaram 15 novos conflitos, sendo a sua maioria em diversas regiōes de África, no Médio Oriente e na Ásia (ACNUR 2015: 17).

Desde logo na Europa, o conflito na Ucrânia que fez disparar o número de solicitaçóes de asilo na Rússia (ib.: 30) e em Portugal, onde 368 dos pedidos de asilo registados até ao final de 2015 foram feitos por ucranianos (CPR 2015). Em África vários conflitos em países como República Centro Africana, Sudão 
do Sul, Nigéria e República Democrática do Congo. Alguns já de longa duração, como na Somália (ACNUR 2015: 10), forçaram 11,4 milhôes de pessoas a deslocarem-se internamente e 3,7 milhōes a tornaram-se refugiados. Na Ásia em 2014 os números apontavam para 3,8 milhóes de refugiados. Excluindo o conflito Sírio, o Afeganistão continua a ser dos principais países de origem dos refugiados devido a conflitos internos que se prolongam há décadas (ib.: 12), para além disso também confrontos entre etnias estão na origem do aumento de refugiados no Myanmar (ib.: 13). No continente americano, apesar de ser dos que gera menos refugiados, destaca-se aqui a Colômbia, devido à insegurança, narcotráfico e confrontos entre gangues urbanas (ib.: 10). Por fim, no médio oriente e norte de África, a primavera árabe que se iniciou em 2011 deu origem a conflitos em países como a Líbia (em 2014 registaram-se 309 mil novos deslocamentos), a Síria e o Iraque, onde há 369.000 refugiados (ib.: 14). A Síria é neste momento, o maior emissor de refugiados, sendo que em 2014 eram já 3, 88 milhôes e este número não pára de aumentar (ib.: 8).

Tudo isto tem feito crescer, progressivamente desde 2010, o número de refugiados, solicitaçóes de asilo e deslocaçóes internas, que no final de 2014 bateu o recorde de 59, 5 milhóes. Deste total, 19,5 milhóes são refugiados, 38,2 milhôes são deslocados internos e 1,8 milhôes são solicitantes de asilo. Só em 2014 houve 13,9 milhóes de pessoas que se tornaram novos deslocados. (ib.: 2) São números que dão que pensar. Esta situação tem consequências nefastas, não só para quem é obrigado a fugir da guerra mas também a nível regional e global. Os países que mais têm acolhido os refugiados não são da Europa, são os países vizinhos e a maior parte são países em desenvolvimento, com poucos recursos. Em 2014, os países que mais refugiados acolheram foram a Turquia (quase 1,6 milhôes), Paquistão (1,5 milhôes) e Líbano (1,15 milhões), seguidos de Irão, Etiópia, Jordânia, Quénia, Chade, Uganda e China (ib.: 12).

Enquanto a Europa se questiona se e como deve acolher vários milhares de refugiados (no fim de 2014, a Europa, tinha acolhido 3,1 milhóes, o que inclui os refugiados acolhidos pela Turquia) e acerca das consequências para a sua economia, os países acima referidos não têm outra opção, sendo que o acolhimento neste caso, implica uma maior pressão nos escassos recursos. O prolongamento desta situaçáo pode revelar-se desastroso, porque o risco de 
propagação de novos conflitos e de choques étnico-culturais é muito maior. Para além de ser urgente sanear os conflitos que estão na origem destas deslocaçóes em massa de pessoas, é ainda mais urgente a partilha global de responsabilidades no auxílio e acolhimento de refugiados. Sobretudo porque, atualmente, além de haver mais refugiados, estes são-no por mais tempo: 2014 foi o ano em que menos pessoas regressaram ao seu país de origem (ib.: 11).

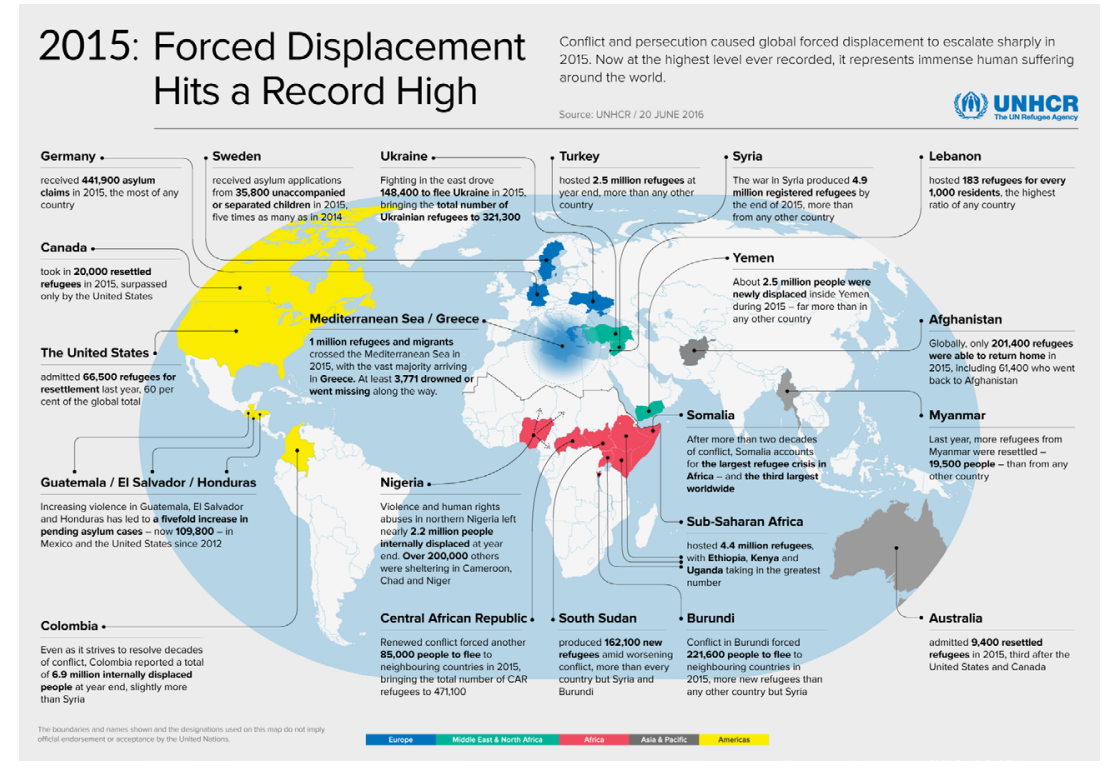

Mapa 1: Tendência globais de deslocamento forçado em 2015.

Fonte UNHCR 2016a

Por fim, analisando a situação portuguesa, dados do Conselho Português para os Refugiados (CPR) revelam que as solicitações de asilo sofreram de 2014 para 2015 um aumento significativo de, 442 para 872 pedidos. Sendo que em 2010 foram registados apenas 160 pedidos. Tanto em 2014, como em 2015 foi a Ucrânia o principal país de origem dos solicitantes de asilo, sendo 
estes, na maioria (63\%) homens. De seguida, muitos dos pedidos vêm de países africanos, como Marrocos, Mali, Serra Leoa, Costa do Marfim, Angola, Guiné Conacri, e República Democrática do Congo, o que se pode explicar quer pela proximidade geográfica e afinidade linguística, como é o caso de Angola, quer pela existência e prolongamento dos conflitos já referidos. Alguns pedidos surgem também de países asiáticos como Paquistão, China e Síria (CPR 2016b).

Apesar da crise humanitária se refletir nos pedidos de asilo em Portugal e mesmo considerando a localização estratégica do país, estes são muito poucos quando comparados com países da Europa do Sul como Espanha, Grécia e Itália, tal como mostra o relatório do ACNUR (2015: 44-45). O que não significa que Portugal esteja de fora desta crise, muito pelo contrário, sendo um problema global, e fazendo Portugal parte da UE e da ONU, terá uma palavra a dizer sobre o assunto e terá também a responsabilidade de agir, acolhendo desde já cerca de 4593 refugiados e procurando tornar os mecanismos de acolhimento e integração mais eficazes.

Não esqueçamos que já em 2016 chegaram à Europa, através do mar mediterrâneo 153, 587 refugiados (até Março), sendo que em 2015 chegaram, $1,015,078$. Analisando as estatísticas mensais das chegadas de refugiados através do mediterrâneo em 2016 e comparando-as com 2015, percebemos que todos os meses têm sido batidos recordes em relação ao ano anterior. Um exemplo para refletirmos: em fevereiro de 2015 chegaram à Europa, por mar, 7,271 pessoas, sendo que em Fevereiro deste ano chegaram já 60, 893 pessoas (UNHCR 2016b).

\section{A BIBLIOTECA PÚBLICA COMO INSTITUIÇÃO QUE PROMOVE A IGUALDADE E A INTEGRAÇÃO}

A biblioteca pública assume desde a sua origem uma preocupação social, tendo a igualdade como um dos seus valores chave e lutando pelo acesso equitativo à informação, pela igualdade de oportunidades e pela integração social. (Marques 2012: 36-43) É, portanto (ou deveria ser), uma das instituições chave quando se trata de preparar um plano de integraçáo de comunidades com necessidades específicas (idosos, pessoas carenciadas, reclusos, pessoas portadoras de deficiência, etc.) ou um plano de integração de comunidades estrangeiras ou minorias étnicas, categorias em que se inserem os refugiados que Portugal já começou a acolher. 
A nível global, a IFLA ${ }^{5}$ e a Unesco têm-se desdobrado em manifestos, diretrizes e recomendaçôes dirigidos às bibliotecas e à comunidade mundial no sentido de alertar para a importância das bibliotecas e do acesso à informaçáo. De facto, o correto processamento da informação, ou seja, o conhecimento tem um poder imbatível quando é partilhado de forma equitativa e na horizontal. Podendo, como fim último, contribuir para a manutenção da paz, ajudando a integrar comunidades minoritárias e ajudar a mudar mentalidades, tornando-nos mais tolerantes e humanos.

No plano nacional ainda pouco se tem feito neste sentido, há serviços especializados por faixa etária, dando especial destaque às crianças e aos idosos. Começa a existir, uma maior sensibilidade para incluir as pessoas portadoras de deficiência (melhores acessibilidades e algum material informativo em braile) mas tem sido dada pouca atençáo às comunidades estrangeiras por parte das bibliotecas. Faltam iniciativas, planos de integração que as incluam e, acima de tudo, falta sensibilidade para com as minorias e uma visão diferente, mais aberta, estratégica e empreendedora em relação às bibliotecas. É necessário deixar de ver as bibliotecas apenas como cofre-forte de livros e fundos de documentaçáo. As bibliotecas podem ser mais do que isso, porque detêm o que atualmente rege a nossa sociedade: a informação.

Neste sentido vale a pena debruçarmo-nos um pouco sobre alguns dos manifestos e diretrizes da IFLA e da Unesco. Comecemos pelo valor da equidade, reiterado logo à cabeça no Manifesto da IFLA/Unesco para as bibliotecas públicas:

Os serviços da biblioteca pública devem ser oferecidos com base na igualdade de acesso para todos, sem distinção de idade, raça, sexo, religião, nacionalidade, língua ou condição social. Serviços e materiais específicos devem ser postos à disposição dos utilizadores que, por qualquer razão, não possam usar os serviços e os materiais correntes, como por exemplo minorias linguísticas, pessoas deficientes, hospitalizadas ou reclusas.

(Unesco 1994)

Sigla de The International Federation of Library Associations and Institutions; ver IFLA 2016. 
Este manifesto já desde 1994 destaca também como missão das bibliotecas públicas "fomentar o diálogo inter-cultural e a diversidade cultural", bem como "assegurar o acesso dos cidadâos a todos os tipos de informaçáo da comunidade local", mostrando claramente que as bibliotecas podem e devem estar na linha da frente, quando se trata da integração de comunidades estrangeiras.

Analisando agora as Diretrizes da IFLA sobre os Serviços da Biblioteca Pública, novamente refere a importância do acesso à biblioteca pública por parte das minorias. Na diretriz 1.6 lê-se:

Deve assegurar-se que os serviços estão igualmente acessíveis a minorias que, por algum motivo, não podem usar os serviços tradicionais, por exemplo, minorias linguísticas, portadores de deficiência física ou sensorial ou residentes em comunidades remotas incapazes de se deslocarem à biblioteca. (IFLA 2013: 18)

De seguida, várias diretrizes prevêem a existência de serviços para as comunidades estrangeiras, bem como de recursos informativos adaptados: na diretriz 3.4.9 sobre a prestação de serviços a grupos especiais de utentes é recomendado que haja "serviços para imigrantes e novos cidadáos, para os ajudar a encontrar o seu caminho numa sociedade diferente e para lhes facultar acesso a materiais da sua cultura de origem". Em consonância, a diretriz 4.3.1 que enumera que coleçôes deve ter uma biblioteca pública, refere "recursos em línguas alternativas da comunidade" e recursos noutras línguas" (ib.: 59) Ainda no mesmo sentido, a diretriz 4.9.2 diz-nos que:

as bibliotecas de comunidades com uma elevada proporção de grupos específicos, como por exemplo crianças, reformados, jovens, populações indígenas, minorias étnicas ou desempregados devem refletir as necessidades destes grupos nas suas coleçóes e serviços.

(IFLA 2013: 64)

Por último, vale a pena analisar o Manifesto da IFLA/Unesco para uma Biblioteca Multicultural. O manifesto foi desenvolvido pela IFLA em 2006 e aprovado pelas duas organizaçóes em 2008. Neste documento, podemos encon- 
trar algumas orientações sobre os princípios e missóes que devem ser inerentes a uma biblioteca multicultural, que recursos devem contemplar, sugestóes de atividades e diretrizes para o pessoal ao serviço. $\mathrm{O}$ manifesto defende a existência de um mundo em que a diversidade cultural e linguística deve ser preservada e respeitada, de forma a cultivar a tolerância e a paz. Como tal: "todos los tipos de bibliotecas deben reflejar, apoyar y promover la diversidad cultural y lingüística en los ámbitos locales, nacionales e internacionales, y de esta manera trabajar por el diálogo intercultural y una ciudadanía activa”(IFLA 2008).

Para além disto, é feito um alerta especial às bibliotecas para darem prioridade aos cidadãos que nas comunidades multiculturais, correm um maior risco de exclusão social: "Se debería prestar especial atención a grupos que a menudo sufren marginación en las sociedades con diversidad cultural: minorías, refugiados y solicitantes de asilo, personas con permisos de residencia temporales, trabajadores inmigrantes y comunidades indígenas" ( $i b$.).

Por fim, é importante referir que a IFLA e a Unesco afirmam a necessidade das bibliotecas elaborarem um plano estratégico de implementação destes serviços, de modo a ir encontro das necessidades de cada uma e da comunidade em que estiver inserida:

La biblioteca debería tener una política y un plan estratégico, que definan su misión, objetivos, prioridades y servicios relacionados con la diversidad cultural. El plan debe basarse en un análisis completo de las necesidades de los usuarios y en recursos adecuados.

(IFLA 2008)

De acrescentar que as duas entidades recomendam a cooperação entre as bibliotecas e as autoridades locais, nacionais e internacionais adequadas para trabalhar com a realidade multicultural.

\section{INFORMAÇÃO PARA O REFUGIADO: QUE SOLUÇÔES?}

Fazendo Portugal parte do leque de países que já acolhe refugiados e sabendo-se que o continuará a fazer, é pertinente refletir acerca da existência ou não 
de um bom sistema de informação para o refugiado. Que soluções existem? A quem podem recorrer?

Embora o CPR tenha até agora disponibilizado intérpretes para acompanharem os refugiados nas primeiras semanas, enquanto não têm um domínio básico da língua portuguesa, a verdade é que, se os refugiados se deslocarem sozinhos a serviços públicos portugueses, estes dificilmente estarão preparados. Para além do português, os funcionários sabem apenas inglês, espanhol ou francês, poucos saberão mais línguas. Ora nem todos os refugiados são fluentes na língua inglesa, que é a língua dominante do mundo ocidental. Depois, se tentarem procurar informaçâo online, encontrarâo diversos sites de entidades portuguesas e internacionais que trabalham com refugiados onde a informação é bastante dispersa, parecendo ser muita ou muito útil.

No entanto vejamos: desde logo o CPR dispóe de um site onde mostra o que faz, os locais de acolhimento e tem ainda alguma informação sobre legislação de migração e asilo e sobre a reinstalação de refugiados... tudo apenas em português. Só dispõe de dois guias em inglês, um com informaçôes de Portugal (CPR 2012) e outro com informação dos programas de reinstalaçáo de refugiados na Europa que direciona os utilizadores para o site European Resettlemet.

Em relação ao site do Serviço de Estrangeiros e Fronteiras (SEF 2016a), acontece o mesmo, é disponibilizada informação variada sobre o SEF, bem como legislaçáo sobre migraçáo e asilo, tudo em português ou em inglês. O SEF disponibiliza ainda uma lista de sites portugueses e europeus (European Resettlement Network 2013), em que sáo poucos os que têm conteúdos noutras línguas como francês, espanhol, alemão, russo ou chinês. Nenhum disponibiliza informação em língua árabe. Depois, consultando o site do Portal do Cidadáo, que poderá ser vital para um estrangeiro em Portugal poder tratar de assuntos burocráticos, verificamos novamente que só há informaçáo em português, inglês e espanhol. Os únicos que o fazem, e muito bem, são a UNHCR (UNHCR 2016c), a agência da ONU para os refugiados. No site da UNHCR é possível encontrar informação acerca da situação dos refugiados em inglês, espanhol, francês, árabe, russo e chinês. Felizmente também a portuguesa PAR - Plataforma de Apoio aos 
Refugiados (PAR 2016), composta por organizaçóes da sociedade civil que pretende ajudar os refugiados, disponibiliza informação em português, inglês e árabe. Aqui podemos encontrar informação sobre a atual crise de refugiados, esclarecendo algumas dúvidas e mitos, indicaçóes de como ajudar os refugiados por intermédio da plataforma, sendo até agora um dos poucos sites portugueses a disponibilizar informação em língua árabe. Também o Alto Comissariado para as Migraçóes (ACM 2016b). embora tenha o seu site apenas em português e inglês e quase toda a página esteja direcionada genericamente para os migrantes, possui informação detalhada sobre Portugal, os direitos dos migrantes, como aprender português e o que precisam fazer para resolver questóes mais práticas do quotidiano, bem como, como para estudar e trabalhar em Portugal. Para além disso, possui um Kit de Acolhimento aos Refugiados (ACM 2016b) bastante completo em Português, Inglês, Francês, Tigrinya (uma das línguas da Etiópia) e Árabe.

Depois de analisarmos estes sites, a maioria tem em comum três coisas: falta de tradução para além do português-inglês, abundância de informação para os imigrantes, pouca informação sobre e para refugiados e dispersão da informação. Á primeira vista, a julgar pela quantidade de sites para imigrantes e refugiados, parece que informação é o que não falta. Na realidade, se observarmos melhor, percebemos que a pouca informaçáo que existe para refugiados, está quase sempre apenas em português e inglês, o que aumenta a probabilidade de muitos refugiados náo conseguirem aceder à mesma. A forma como está estruturado o sistema de informação para imigrantes, reflete que Portugal foi durante muitos anos um país de imigrantes e mostra que ainda não está bem preparado para acolher devidamente refugiados. $\mathrm{O}$ que se explica porque, embora Portugal já tenha acolhido 180 refugiados entre 2006 e 2014, através do Programa Nacional de Reinstalação (CPR 2015: 10) e de o CPR estimar que, no fim de 2014, viviam em Portugal 350 refugiados (ib.: 6), só agora é que é preciso acolher vários milhares de refugiados. Estes cidadãos reúnem uma série de caraterísticas específicas que é fundamental considerar: desde logo por não se estarem a deslocar voluntariamente e por trazerem consigo um passado, muitas vezes traumático, de perdas, perseguição e guerra. 


\section{ACOLHIMENTO: QUE PLANO DE INTEGRAÇÁO?}

A integração de refugiados em Portugal tem sido coordenada pelo CPR que tem feito um trabalho notável. Para perceber como funciona o processo de integração, analisámos o seu último relatório anual de atividades. Percebemos que desde 1991 o CPR em coordenação com entidades a nível local (autarquias e escolas, sobretudo de Lisboa), nacional (SEF, IEFP, etc.) internacional, embora atuando numa escala menor do que será necessário no futuro, o CPR uniu esforços e conseguiu integrar, com sucesso, centenas de refugiados. O plano nacional de integração de refugiados, elaborado em 2008, já está desatualizado, estando atualmente a ser criado um novo pelas autoridades competentes. No entanto até agora tem sido feito o seguinte: o primeiro passo é o acolhimento dos refugiados e/ou requerentes de asilo pelo CPR, num dos seus Centros de Acolhimento para Refugiados. Aqui começa o processo de integraçáo, procurando-se resolver as questôes burocráticas, jurídicas e profissionais, para a legalização e concessáo de autorização de residência dos refugiados. Durante a estadia nos centros, os refugiados aprendem a língua nacional e recebem formação profissional para que se possam adaptar e ser competitivos no mercado de trabalho português. São também desenvolvidas atividades como visitas a museus e monumentos, idas ao teatro e atividades lúdicas, por exemplo, a comemoraçáo de dias históricos, para estimular a aprendizagem da língua e da cultura portuguesas, combater o isolamento e torná-los mais autónomos.

Sem emprego e sem dominar a língua do país de acolhimento, a integração dos refugiados fica seriamente comprometida. Arranjar emprego é dos principais entraves, porque na maioria dos casos implica uma mobilidade profissional em sentido descendente ou numa profissão diferente da que tinham anteriormente. Isto acontece ou porque alguns refugiados não trazem consigo documentos de identificação, o que torna mais difícil a sua legalização ou por dificuldades em comprovar as suas habilitaçóes académicas e/ou vê-las reconhecidas pelo Estado Português.

$\mathrm{O} C P R$ dá especial atenção às crianças, existindo um centro de acolhimento destinando apenas a menores náo-acompanhados, para que possam ter um acompanhamento especializado e, quando é possível, promover o reagrupamento familiar. Também para promover a integração e a aprendizagem da língua, o CPR desenvolve alguns projetos artísticos, destacando-se, o grupo de teatro amador, RefugiActo, já com dez anos de existência (CPR 2015: 21). 
É importante referir que o trabalho do CPR não acaba na ajuda direta aos refugiados, vai mais longe, procurando alertar a comunidade nacional para esta causa e para a importância de uma boa integração dos refugiados. Não nos podemos esquecer que o processo de integração não é unilateral: o esforço de integração não deve apenas partir de quem vem de fora, deve ser feito com a ajuda das comunidades do país de acolhimento. Como tal, o CPR promove açôes de informação pública como a IX Conferência Internacional do CPR que ocorreu em 2014, a comemoração do Dia Mundial do Refugiado, anualmente a 20 de Junho e ações de informação e sensibilização em escolas e universidades. Organiza também visitas aos centros de acolhimento de refugiados e ministra formação e-learning de sensibilização para o asilo e refugiados (ib.: 24-26).

Por fim, é de notar que, no trabalho desenvolvido pelo CPR raramente são mencionadas as bibliotecas públicas. No relatório de atividade de 2014 apenas é referida uma visita à biblioteca municipal da Amadora (ib.: 20) e, curiosamente, o papel da biblioteca/mediateca do centro de acolhimento de refugiados, que apesar de náo funcionar a tempo inteiro:

A abertura da Biblioteca/Mediateca é muito importante, não só como forma de divulgaçáo temática especializada do Direito de Asilo e Direitos Humanos junto da comunidade de acolhimento, mas, também, como forma de ocupaçáo dos tempos livres dos beneficiários do Centro e de apoio à aprendizagem da língua portuguesa (tendo um acolhimento cada vez maior por parte dos refugiados, quer internos, quer aqueles que já saíram do Centro e continuam a procurar os seus serviços).

(CPR 2015: 28)

A importância desta biblioteca para os refugiados, prova de novo a necessidade de integrar as bibliotecas públicas nos planos de acolhimento. A propósito, é importante referir um projeto que é um exemplo na promoção da integração de refugiados, a Human Library Organization ${ }^{6}$. Este projeto nasceu

\footnotetext{
6 Para saber mais acerca do projeto aceda-se a: http://humanlibrary.org/ (consultado a 21/09/2016).
} 
na Dinamarca em 2000, consiste num espaço em que não se requisitam livros, mas sim pessoas, cada uma com um problema ou estigma. Depois de requisitadas são ouvidas como quem folheia um livro, contando os seus testemunhos de vida, sendo que os dicionários são os voluntários ou funcionários das $\mathrm{ONG}$ que recriam o projeto e que servem de tradutores entre os livros humanos e os seus leitores. O projeto já está em países como Estados Unidos, Canadá, Polónia, Chipre e Dinamarca.

\section{A CRIAÇÁO DE SERVIÇOS DE INFORMAÇÁO PARA REFUGIADOS: PRINCÍPIOS ORIENTADORES}

A criação deste serviço pela sua especificidade humana e cultural e porque, no caso português, é uma novidade, necessita ser pensada de forma a criar de raiz um serviço de informação multicultural, bem estruturado, eficaz e em articulação com a comunidade. Deve ter como princípios base, tal como afirmam o Manifesto da IFLA/Unesco para uma biblioteca multicultural e as diretrizes da IFLA “Comunidades multiculturales: directrices para el servicio bibliotecário", a equidade e o respeito pela diversidade cultural. Depois, como nos explica a IFLA, é essencial conhecer bem cada comunidade: as caraterísticas socioeconómicas da população e as entidades locais, administrativas e da sociedade civil, de modo a elaborar um serviço que inclua toda a comunidade (IFLA 2009: 9-12).

Esta será a melhor forma de, em países como Portugal, onde as bibliotecas não têm ainda uma ligação estreita com as comunidades e, onde escasseiam recursos financeiros, se prestar um bom serviço de informação aos refugiados. Além disso, é importante conhecer bem os cidadãos refugiados instalados em cada comunidade para criar um serviço ajustado às suas caraterísticas. Será importante saber qual a sua língua materna, que idiomas dominam, as suas idades, habilitaçóes académicas, se estão ou não familiarizados com o conceito de biblioteca pública, etc. Este levantamento de informação deverá ser feito pelas autoridades administrativas centrais (SEF ou CPR) que depois deveram passar essa informação à administração local. Havendo um serviço de informação multicultural já implementado, estas informações serão úteis para reajustar o serviço às necessidades dos novos habitantes, por exemplo, 
para obter recursos informativos em idiomas específicos (ib.: 9-12). Este será, um dos principais desafios dada a variedade de idiomas existentes e a dificuldade de obter recursos em alguns deles. Outro grande desafio, para o qual o pessoal ao serviço deverá estar preparado, é a questão das diferenças culturais. Os refugiados não estão familiarizados com os valores e padróes de vida ocidentais. A cultura da tolerância e do respeito deverá começar no pessoal ao serviço (ib.: 21-22).

As diretrizes da IFLA para as comunidades multiculturais constituem uma boa base para estruturar estes serviços: dão orientaçóes acerca dos princípios e objetivos que devem estabelecidos, bem como indicaçóes acerca da constituição e manutenção das coleçóes. Chamam ainda a atenção para a importância da constituição duma equipa multidisciplinar, devendo o serviço ser um produto da uniáo de esforços humanos e institucionais das autoridades locais (ib.: 7-23).

Finalizando, as diretrizes referem ainda exemplos de boas práticas de países estrangeiros onde estes serviços têm sido bem-sucedidos. Não é por acaso que a maioria dos países referidos são anglo-saxónicos (Canadá, Austrália, EUA, Inglaterra) ou do norte da europa (Dinamarca, Estónia, Países Baixos, Noruega). Este facto explica-se pelas largas décadas de tradição da biblioteca pública nestes países onde têm uma forte implementação devido à existência de um olhar mais estratégico e consciente da sua importância e potencial (ib.: 24-32).

Um bom serviço de informação multicultural deverá garantir o ensino da língua e da cultura portuguesas. Para os que não estáo familiarizados com informática e internet, é necessário dar formação sobre como consultar recursos online. Será também muito importante disponibilizar recursos informativos variados (monografias, publicaçóes periódicas) e recursos multimédia (filmes, música, etc.) de países como a Síria, Egipto, Líbia, Somália, Ucrânia, Paquistão, Mali, no maior leque de idiomas possível ( $i b$.: 12-16). Estes recursos terão uma dupla finalidade: ajudar os refugiados a sentirem-se mais integrados e dar oportunidade à comunidade local de conhecer melhor a cultura das pessoas que está a acolher, fomentando-se assim o diálogo intercultural. Também neste sentido é fundamental criar 
programas de lazer, para dar lugar ao encontro de culturas e partilha de experiências (ib.: 6).

Por fim, tal como referido nas diretrizes, deve ser feito o esforço de disponibilizar a informaçấo dos sites das bibliotecas e dos catálogos online, também no maior número de maior de idiomas possível. O mesmo deve ser feito para todos os sites cuja consulta seja relevante para os refugiados, por exemplo, o site da câmara municipal (ib.: 19-20).

\section{CONCLUSÃO}

Ao desenvolver esta investigação percebemos que, a História do século passado parece estar a repetir-se, não temos uma guerra mundial, mas temos uma série de conflitos em diversos pontos do globo, não há campos de concentração, mas há centenas de campos de refugiados onde milhares de pessoas estão sem as mais básicas condiçôes de vida.

Perante este cenário, e à semelhança do que aconteceu há 77 anos com a criação dos $\mathrm{CAB}$, concluímos que é necessário agir. Sendo as bibliotecas públicas instituiçôes que promovem a igualdade e a integraçáo social e cultural deverão ter voz na elaboração de planos de integração dos refugiados e promover a criação de serviços de informação para os mesmos. Concluímos também que Portugal apesar de ser, frequentemente, um país de acolhimento de imigrantes, ainda não está preparado para acolher vários milhares de refugiados, que será necessário acolher no futuro. Isso reflete-se, quer na forma como a informação para refugiados tem vindo a ser disponibilizada: dispersa, e quase sempre em apenas duas línguas, como também no modo de acolhimento das parcas centenas de refugiados que têm chegado a Portugal. Apesar do excelente trabalho do $\mathrm{CPR}$, as estruturas que possui e o atual modelo de acolhimento, não parecem estar preparados para acolher um grande número de refugiados.

Concluímos por fim, que a disponibilização de recursos multiculturais para toda a população, será a chave para a efetiva integração dos refugiados, bem como para minorar comportamentos xenófobos e choques étnicos. Apenas o conhecimento das diversas realidades culturais e da sua História nos pode tornar pessoas mais esclarecidas, tolerantes e humanas. 


\section{BIBLIOGRAFIA}

ACM (2016). Bem-vindo. http://www.acm.gov.pt/inicio (consultado a 21/9/2016).

ACM (2016b). Kit de Acolhimento aos Refugiados. http://www.acm.gov.pt/kitrefugiados (consultado a 21/9/2016).

ACNUR (2015). Mundo en Guerra: Tendencias globales desplazamiento forzado en 2014. http://www.acnur.org/t3/fileadmin/scripts/doc.php?file=t3/fileadmin/Documentos/Publicaciones/2015/10072 (consultado a 21/9/2016).

ACNUR (2016a) Breve histórico do ACNUR. http://www.acnur.org/portugues/informacao-geral/ breve-historico-do-acnur (consultado a 21/9/2016).

ACNUR (2016b). Convenção relativa ao estatuto dos refugiados. http://www.acnur.org/t3/filead$\mathrm{min} /$ scripts/doc.php?file=t3/fileadmin/Documentos/portugues/BDL/Convencao_relativa_ao_Estatuto_dos_Refugiados (consultado a 21/9/2016).

Almeida, Filipa Rino (2015). O impacto social da informação: a prestação do serviço de informação à comunidade. Acedido em Repositório Institucional da Universidade de Coimbra (https:// estudogeral.sib.uc.pt/handle/10316/29855) (consultado a 25/2/2016).

Citizens Advice Bureau (2009). A History of the Citizens Advice Bureau. http://www.ashcab.org. uk/CAB\%20history\%201939-2009.pdf (consultado a 22/2/2016).

CPR (2012). Welcome to Portugal: Cultural Orientation Leaflet for Resettled Refugees in Portugal. http://refugiados.net/1cpr/www/reinstalacao/welcome_to_portugal_19jul_2012final.pdf (consultado a 21/9/2016).

CPR (2015). Relatório Anual de Atividades do Conselho Português dos Refugiados em 2014. http:// www.cpr.pt/ (consultado a 21/9/2016).

CPR (2016). Conselho Português para os refugiados. http://www.cpr.pt/ (consultado a 22/3/2016).

CPR (2016b). Dados estatísticos. http://www.cpr.pt/ (consultado a 22/3/2016).

Diário da República Eletrónico (2016). Declaração Universal dos Direitos Humanos. https://dre. pt/declaracao-universal-dos-direitos-humanos (consultado a 21/9/2016).

European Resettlement Network (2013). National Resettlement Programmes. http://www.resettlement.eu/country (consultado a 21/9/2016).

Fraser, Derek (2009). The Evolution of the British Welfare State: a History of Social Policy since the Industrial Revolution. Basingstoke: Palgrave Macmillan.

Gilbert, Martin (2010). História do século XX. Trad. Francisco Agarez. Alfragide: Dom Quixote. 


\section{FILIPA RINO ALMEIDA}

Gonçalves, Marta (23/9/2015). "Chegarão aos poucos. Portugal vai receber 4593 refugiados”, Expresso. http://expresso.sapo.pt/internacional/2015-09-22-Chegarao-aos-poucos.-Portugal-vai-receber-4593-refugiados- (consultado a 21/9/016).

Governo de Portugal (2016). Portal do Cidadão. https://www.portaldocidadao.pt/home (consultado a $21 / 9 / 2016)$.

Human Library (2016). The human library organization. http://humanlibrary.org/ (consultado a 21/3/2016).

IFLA (2008). Manifesto IFLA/UNESCO por la biblioteca multicultural. http://www.ifla.org/files/ assets/library-services-to-multicultural- (consultado a 21/9/2016).

IFLA (2009). Comunidades multiculturales: directrices para el servicio bibliotecário. 3. ${ }^{\mathrm{a}} \mathrm{ed}$. http:// www.ifla.org/files/assets/library-services-to-multicultural- (consultado a 21/9/2016).

IFLA (2013). Diretrizes da IFLA sobre os serviços da Biblioteca Pública. Lisboa: Direção-Geral do Livro, dos Arquivos e das Bibliotecas. http://www.ifla.org/files/assets/hq/publications/ series/147-pt.pdf (consultado a 21/9/2016).

IFLA (2016). About IFLA. http://www.ifla.org/about (consultado a 21/9/2016).

Judt, Tony (2007). Pós-guerra: história da Europa desde 1945. Trad. Vítor Silva, Maria Manuel Cardoso da Silva, Patrícia Xavier. Lisboa: Edições 70.

Marques, Maria Beatriz Pinto de Sá Moscoso (2012). A satisfação do cliente de serviços: as bibliotecas públicas da regiāo centro. Tese de Doutoramento. https://estudogeral.sib.uc.pt/handle/10316/20462 (consultado a 21/9/2016).

OECD (2015). "Is this humanitarian migration crisis different?" Migration Policy Debates, 7. https://www.oecd.org/migration/Is-this-refugee-crisis-different.pdf (consultado a 21/9/2016).

PAR (2016). Plataforma de Apoio aos Refugiados. http://www.refugiados.pt/ (consultado a $21 / 9 / 2016)$.

UNESCO (1994). Manifesto da Unesco sobre Bibliotecas Públicas. http://archive.ifla.org/VII/s8/ unesco/port.htm (consultado a 21/9/2016).

UNHCR (2016a). Global trends 2015: forced displacement hits a record hight. http://www.unhcr. org/global-trends-2015.html (consultado a 21/9/2016).

UNHCR (2016b). Refugees/Migrants Emergency Response-Mediterranean. http://data.unhcr.org/ mediterranean/regional.php (consultado a 21/9/2016).

UNHCR (2016c). The UN Refugee Agency. Acedido em: http://www.unhcr.org/cgi-bin/texis/vtx/ home (consultado a 21/9/2016). 
A criação de serviços de informação para refugiados

United States Holocaust Memorial Museum (2016). Vitimas do periodo nazi: ideologia racial nazi. https://www.ushmm.org/wlc/ptbr/article.php?ModuleId=10007457 (consultado a 21/11/2016).

Working Party on Community Information (1980). Community Information: what libraries can do. London: Library Association. 